\section{OVERVIEW OF THE CHILDHOOD SYSTEMIC LUPUS ERYTHEMATOSUS (CSLE) COHORT IN THE CARRA REGISTRY}

${ }^{1}$ Christine Bacha, ${ }^{2}$ Andrea Knight, ${ }^{3}$ Laura Schanberg, ${ }^{4}$ Mary Beth Son, ${ }^{5}$ Emily von Scheven, ${ }^{6}$ Aimee Hersh*, for the CARRA Registry Investigators. ${ }^{1}$ Division of Pediatric Rheumatology, Nationwide Children's Hospital; ' ${ }^{2}$ Division of Pediatric Rheumatology, Hospital for Sick Children; ${ }^{3}$ Division of Pediatric Rheumatology, Duke University Hospital; ${ }^{4}$ Division of Immunology, Boston Children's Hospital; ${ }^{5}$ Division of Pediatric Rheumatology, UCSF Benioff Children's Hospital; ${ }^{6}$ Division of Pediatric Rheumatology, University of Utah

\subsection{6/lupus-2021-lupus21century.53}

Background The Childhood Arthritis and Rheumatology Research Alliance (CARRA) Registry is a multi-center, observational registry that collects demographic, clinical, and providerand patient-reported data from patients with pediatric-onset rheumatic diseases in North America, Israel and Italy. This study aimed to describe the demographic features, cumulative clinical manifestations, and treatments of the childhood systemic lupus erythematosus (cSLE) cohort within the CARRA Registry.

Abstract 1110 Table 1 Sociodemographic characteristics of the CARRA cSLE Registry Cohort at enrollment

\begin{tabular}{|l|c|}
\hline \multicolumn{1}{|c|}{ Characteristics } & $\mathbf{N}=671$ \\
\hline Gender, $\mathbf{n}$ (\%) & \\
\hline Male & $99(14.8)$ \\
\hline Female & $572(85.3)$ \\
\hline Age at enrollment (years) & \\
\hline Median & 15 \\
\hline Mean (SD) & $14.3(2.9)$ \\
\hline IQR & $11-15$ \\
\hline Race/ethnicity (self-reported), $\mathbf{( \% )}$ & \\
\hline White & $175(26.1)$ \\
\hline Black & $199(29.7)$ \\
\hline Hispanic & $155(23.1)$ \\
\hline American Indian/Alaskan native & $8(1.2)$ \\
\hline Asian & $99(14.8)$ \\
\hline Middle Eastern/North African & $7(1)$ \\
\hline Native Hawaiian/Pacific Islander & $3(0.5)$ \\
\hline Other & $12(1.8)$ \\
\hline Prefer not to answer/Missing & $13(1.9)$ \\
\hline Insurance, $\mathbf{n}$ (\%) & \\
\hline Private & $312(46.5)$ \\
\hline Public insurance & $277(41.3)$ \\
\hline Uninsured & $17(2.5)$ \\
\hline Other & $65(9.7)$ \\
\hline Income, $\mathbf{n}$ (\%) & $64(9.5)$ \\
\hline$<25,000$ & $62(9.6 .5)$ \\
\hline $25,000-49,999$ & $60(8.9)$ \\
\hline $50,000-74,999$ & \\
\hline $75,000-99,999$ & \\
\hline $100,000-150,000$ & \\
\hline$\geq 150,000$ & \\
\hline Prefer not to answer/Unknown & \\
\hline
\end{tabular}

$I Q R$, interquartile range
Methods Since 2015, the CARRA Registry has enrolled 10,411 patients at 70 centers. Childhood-onset SLE enrollment began in March 2017. We performed a retrospective cohort study of patients with cSLE enrolled in the US between March 2017 to December 2020. Inclusion criteria for participants in the CARRA cSLE Registry include: 1) diagnosis of cSLE at $<18$ years based on American College of Rheumatology (ACR) or Systemic Lupus Erythematosus International Collaborating Clinics (SLICC) ; 2) enrollment within two years of cSLE diagnosis or at the time of a flare of lupus nephritis; and 3) enrollment prior to 21 years of age. Sociodemographic and clinical data were summarized using descriptive statistics.

Results The current registry cohort includes 671 participants with cSLE. The majority are female $(85 \%)$ with mean age at enrollment of 14.3 (SD 2.9) years. The cohort is both ethnically and racially diverse (table 1). Socioeconomic status varies widely, noting $12.5 \%$ having a household income below $\$ 25,000 /$ year. The median time from symptom onset to diagnosis was two months (interquartile range (IQR) 25 days to 6 months), from diagnosis to enrollment was 5 (IQR 1-15) months, and from enrollment to end of follow up was 14 (IQR 6 to 23) months. At the end of the follow-up period, more than $60 \%$ of participants developed nephritis as defined by ACR or SLICC criteria. $6.1 \%$ and $10 \%$ had neurological manifestations per ACR and SLICC criteria, respectively (table 2). Systemic Lupus Erythematosus Disease Activity Index (SLEDAI) at enrollment was a median of 4 (IQR 2-10). Most patients were prescribed hydroxychloroquine. In the first 2-3 years of disease, participants received a variety of immunosuppressive therapies including Mycophenolate Mofetil, Cyclophosphamide, Azathioprine, Rituximab, Belimumab and disease

Abstract 1110 Table 2 Prevalence of the American College of Rheumatology (ACR) classification Criteria and SLICC Classification Criteria in a CSLE cohort $(\mathrm{N}=671)$

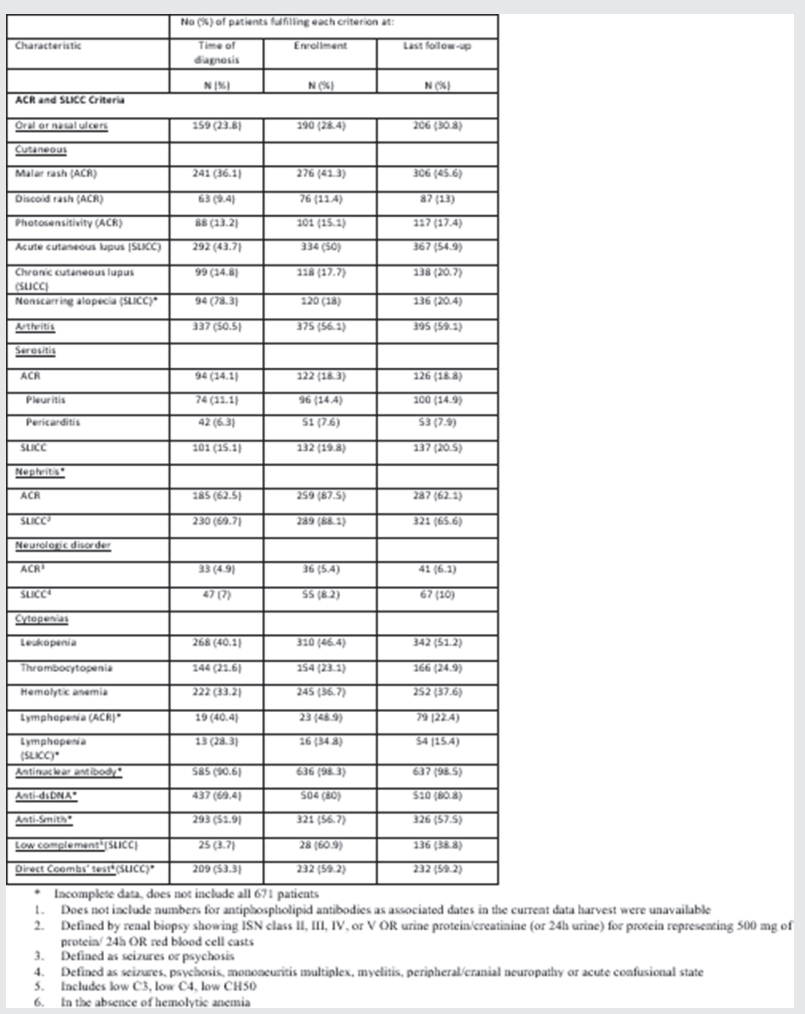


Abstract 1110 Table 3 Immunosuppressive treatment in the CARRA CSLE Registry Cohort ( $\mathrm{N}=671)$

\begin{tabular}{|l|c|c|}
\hline Medication & $\begin{array}{c}\text { Ever Prescribed } \\
\text { N (\%) }\end{array}$ & $\begin{array}{c}\text { Currently prescribed } \\
\text { N (\%) }\end{array}$ \\
\hline Steroids & $614(83.7)$ & $308(42)$ \\
\hline Oral & $569(77.5)$ & $305(41.6)$ \\
\hline Intravenous & $319(43.5)$ & $15(2)$ \\
\hline Hydroxychloroquine & $631(94)$ & $598(89.1)$ \\
\hline Mycophenolate Mofetil & $373(55.6)$ & $295(44)$ \\
\hline Cyclophosphamide & $97(14.5)$ & $22(3.3)$ \\
\hline Azathioprine & $131(19.5)$ & $81(12.1)$ \\
\hline Rituximab & $131(16.7)$ & $28(4.1)$ \\
\hline Belimumab & $32(4.9)$ & $28(4.2)$ \\
\hline Other $^{1}$ & $113(16.8)$ & $60(8.9)$ \\
\hline
\end{tabular}

modifying anti-rheumatic drugs such as Leflunomide and Methotrexate. $84 \%$ of patients were prescribed either oral or intravenous glucocorticoids during their disease course (table 3).

Conclusions The CARRA Registry has enrolled a racially and ethnically diverse cohort of cSLE patients in the early course of their disease. These participants exhibit moderate disease activity and although the use of hydroxychloroquine in this cohort is high, a significant proportion of patients are utilizing glucocorticoids at the last study visit. We anticipate enrolling a minimum of 1000 participants with more than ten years of follow-up. This cohort, which is one of the Centers for Disease Control (CDC) funded SLE registries, provides a unique opportunity to describe the natural history, treatments, and outcomes in patients with cSLE.

\section{INCREASING ACCESS AND QUALITY OF CARE FOR INDIVIDUALS FROM UNDERREPRESENTED COMMUNITIES LIVING WITH LUPUS: INSIGHTS FROM QUALITATIVE INTERVIEWS WITH PATIENTS AND PHYSICIANS}

1,2Saira Z Sheikh*, ${ }^{3}$ Maria L Naylor, ${ }^{3}$ Lasair O'Callaghan, ${ }^{3}$ Lina Sladkeviciute, ${ }^{3}$ Janine GaihaRohrbach, ${ }^{3}$ Cherie Butts. 'University of North Carolina at Chapel Hill, Thurston Arthritis Research Center, Chapel Hill, NC, USA; ${ }^{2}$ University of North Carolina at Chapel Hill School of Medicine, Department of Medicine, Division of Rheumatology, Allergy and Immunology, Chapel Hill, NC, USA; ${ }^{3}$ Biogen, Cambridge, MA, USA

\subsection{6/lupus-2021-lupus21century.54}

Background Lupus disproportionately affects Black/African American (AA) and Latino/a patients, yet these underrepresented racial/ethnic minority populations often face challenges with accessing quality care. ${ }^{1,2}$ We aimed to explore patients'

\section{Abstract 1111 Table 1 Demographics of Patient and Physician Participants}

\begin{tabular}{lll}
\hline Characteristic, $\mathrm{n}(\%)$ & $\begin{array}{l}\text { Patients }^{\mathrm{a}} \\
(\mathrm{n}=33)\end{array}$ & $\begin{array}{l}\text { Physicians }^{\mathrm{a}} \\
(\mathbf{n}=20)\end{array}$ \\
\hline Patient age & & \\
$18-35$ years & $4(12)$ & NA \\
$36-65$ years & $26(79)$ & NA \\
$66+$ years & $3(9)$ & NA \\
Female & $29(88)$ & NA
\end{tabular}

\begin{tabular}{|c|c|c|}
\hline \multicolumn{3}{|l|}{ Race/Ethnicity } \\
\hline Black/African American & $16(48)$ & $2(10)$ \\
\hline Latino/a & $10(30)$ & 0 \\
\hline Asian/Pacific Islander & $5(15)$ & $4(20)$ \\
\hline Native American & $2(6)$ & $1(5)$ \\
\hline White/Caucasian & 0 & $12(60)$ \\
\hline Prefer not to disclose & 0 & $1(5)$ \\
\hline \multicolumn{3}{|l|}{ Region } \\
\hline Northeast & $11(33)$ & $8(40)$ \\
\hline Midwest & $5(15)$ & $1(5)$ \\
\hline South & $12(36)$ & $8(40)$ \\
\hline West & $5(15)$ & $3(15)$ \\
\hline \multicolumn{3}{|l|}{ Education level } \\
\hline Some high school or less ${ }^{b}$ & $2(6)$ & 0 \\
\hline Some college & $8(24)$ & 0 \\
\hline Graduated college/technical school & $17(52)$ & 0 \\
\hline Postgraduate degree & $6(18)$ & $20(100)$ \\
\hline \multicolumn{3}{|l|}{ Employment status } \\
\hline Full time & $11(33)$ & NA \\
\hline Part time & $4(12)$ & NA \\
\hline Other ${ }^{c}$ & $18(55)$ & NA \\
\hline \multicolumn{3}{|l|}{ Type of lupus } \\
\hline SLE & $23(70)$ & NA \\
\hline CLE & $4(12)$ & NA \\
\hline Other ${ }^{\text {d }}$ & $6(18)$ & NA \\
\hline \multicolumn{3}{|l|}{ Severity of lupus } \\
\hline Mild & $4(12)$ & NA \\
\hline Moderate & $23(70)$ & NA \\
\hline Severe & $6(18)$ & NA \\
\hline Physician specialty & NA & \\
\hline Rheumatology & NA & $11(55)$ \\
\hline Dermatology & NA & $9(45)$ \\
\hline \multicolumn{3}{|l|}{ Investigator vs referring physician } \\
\hline Referring physician & NA & $14(70)$ \\
\hline Investigator & NA & $6(30)$ \\
\hline \multicolumn{3}{|l|}{ Years experience post-residency } \\
\hline $5-19$ years & NA & $13(65)$ \\
\hline $20+$ years & NA & $7(35)$ \\
\hline \multicolumn{3}{|l|}{ Physician practice: patient race } \\
\hline $\begin{array}{l}\text { Majority Black or African American (> } 50 \% \text { of } \\
\text { patients) }\end{array}$ & NA & $7(35)$ \\
\hline Majority White/Caucasian ( $>50 \%$ of patients) & NA & $4(20)$ \\
\hline Mix (all races $<50 \%$ of patients) & NA & $9(45)$ \\
\hline \multicolumn{3}{|l|}{ Physician practice: patient insurance coverage } \\
\hline $\begin{array}{l}\text { Physicians with commerically/privately insured (> 50\% } \\
\text { of patients) }\end{array}$ & NA & $11(55)$ \\
\hline Physicians with Medicare insured ( $>50 \%$ of patients) & NA & $1(5)$ \\
\hline $\begin{array}{l}\text { Physicians with mix (private and Govt insured, all }< \\
50 \% \text { of patients) }\end{array}$ & NA & $8(40)$ \\
\hline
\end{tabular}

CLE = cutaneous lupus erythematosus; NA = not applicable or data not available; SLE = systemic lupus erythematosus.

aPatient participants were recruited from a database of individuals who agreed to be contacted for research purposes. Interviews were conducted between November 2020 and January 2021 (patients) and between December 2020 and February 2021 (physicians). ${ }^{b}$ Includes 1 patient who was currently in school.

Includes on disability $(n=8)$, retired $(n=4)$, homemaker $(n=4)$, unemployed, looking for work $(n=1)$, and student $(n=1)$.

dIncludes both SLE and CLE $(n=3)$ and unknown/not sure $(n=3)$.

and physicians' perceptions on the treatment journey for underrepresented patients and identify barriers to quality care. Methods In-depth qualitative interviews were conducted with patients with lupus from underrepresented populations (Black/ AA, Latino/a, Native American, Asian/Pacific Islander) and 